\title{
Differential sensitization of two human colon cancer cell lines to the antitumor effects of irinotecan combined with 5-aza-2'-deoxycytidine
}

\author{
SHUKO HAKATA ${ }^{1}$, JUN TERASHIMA ${ }^{1}$, YU SHIMOYAMA ${ }^{2}$, KOUJI OKADA ${ }^{1,3}$, \\ SHIHO FUJIOKA ${ }^{1}$, ERIKA ITO ${ }^{1}$, WATARU HABANO ${ }^{1}$ and SHOGO OZAWA $^{1}$
}

\begin{abstract}
${ }^{1}$ Department of Pharmacodynamics and Molecular Genetics, School of Pharmacy; ${ }^{2}$ Division of Molecular Microbiology, Iwate Medical University, Yahaba-cho, Iwate 028-3694; ${ }^{3}$ Department of Clinical Pharmaceutics and Pharmacy Practice, School of Pharmacy, Tohoku Medical and Pharmaceutical University, Sendai-shi, Miyagi 983-8512, Japan
\end{abstract}

Received June 12, 2017; Accepted December 14, 2017

DOI: $10.3892 / 01.2018 .7883$

\begin{abstract}
Irinotecan (CPT-11) is a key therapeutic drug used in the treatment of colorectal cancer, although acquired or constitutive resistance to CPT-11 (and its activated metabolite SN-38) can lead to tumor progression. Since the acquisition of drug resistance can result from DNA hypermethylation, the antitumor activity of CPT-11 and SN-38 was assessed in combination with a known DNA methyltransferase inhibitor, 5-aza-2'-deoxycytidine, also known as decitabine (DAC). DAC potentiated the antitumor activity of CPT-11 additively, and that of SN-38 synergistically, as measured by colony formation in the human colorectal cancer HCT116 cell line. No DAC potentiation of these antitumor effects was observed with another human colorectal cancer HT29 cell line. Anti-apoptotic B-cell lymphoma-2 (Bcl-2) protein expression was reduced to $50-67 \%$ of the control following a single treatment with CPT-11, SN-38, or DAC, and was markedly reduced to $7-8 \%$ following the combination of CPT-11/SN-38 with DAC. By contrast, Bcl-2 protein expression was barely detected in HT29. Wilms' tumor protein (WT1), which has been shown to be a positive regulator of Bcl-2 in HCT116 cells through WT1-kncokdown experiments, was downregulated in HCT116 and HT29 cells when treated with CPT-11/SN-38 combined
\end{abstract}

Correspondence to: Professor Shogo Ozawa, Department of Pharmacodynamics and Molecular Genetics, School of Pharmacy, Iwate Medical University, 2-1-1, Nishitokuta, Yahaba-cho, Iwate 028-3694, Japan

E-mail: sozawa@iwate-med.ac.jp

Abbreviations: CPT-11, irinotecan; CRC, colorectal cancer; DAC, 5-aza-2'-deoxycytidine; DNMT, DNA methyltransferase; SN-38, 7-ethyl-10-hydroxycamptothecin

Key words: DNA methyltransferase inhibitor, irinotecan, SN-38, 5-aza-2'-deoxycytidine, decitabine, human colon cancer HCT116 cells, human colon cancer HT29 cells, B-cell lymphoma-2, Wilms' tumor gene 1 with DAC, with decreases greater than any single administration of CPT-11, SN-38, or DAC. The extent of CPT-11/SN-38 potentiation by DAC may depend on Bcl-2 expression levels in human colorectal cancer cells.

\section{Introduction}

The International Agency for Research on Cancer (IARC) has reported in recent years that colorectal cancer (CRC) is the 3rd most common cancer type based on the number of cancer cases worldwide. According to the estimates of world cancer incidence rates, the number of CRC cases was $\sim 1,360,000$ (9.7\% in total) for the two sexes (1). Chemotherapy is an important treatment strategy for CRC, and one of the key chemotherapeutic drugs for treating metastatic CRC is irinotecan (CPT-11). CPT-11, which is the standard drug for treatment of CRC, can be converted by carboxylesterase to the active metabolite $\mathrm{SN}-38$, which has even greater antitumor activity, inhibiting DNA topoisomerase I through the formation of stable topoisomerase I-DNA cleavable complexes (2-4). The resulting DNA damage can lead to cell cycle arrest and/or cell death by apoptosis (5). However, acquired or constitutive resistance to $\mathrm{SN}-38$ does occur, allowing for tumor progression (6).

One cause of tumor initiation, progression, and drug resistance acquisition is aberrant DNA hypermethylation. In tumors, DNA hypermethylation mediates epigenetic changes that silence gene expression without altering nucleotide sequences. 5-Aza-2'-deoxycytidine (DAC) is a DNA methyltransferase (DNMT) inhibitor, a DNA demethylating agent, and a cell cycle-arresting agent (7-9). Preliminary studies have been conducted on the combined use of DNMT inhibitors with existing antitumor agents (10-12). Accordingly, a preliminary experiment was conducted on a combination of a specific antitumor agents, including CPT-11, SN-38 or 5-FU with one of several epigenetic modifiers including DAC in two different human CRC cell lines; HCT116 and HT29 (13). Marked enhancement of the antitumor activities of CPT-11 or SN-38 with DAC was observed in HCT116 cells, but not in HT29 cells. The potentiation of CPT-11/SN-38 by DAC was associated 
with decreased expression of the B-cell lymphoma-2 (Bcl-2) protein. The Bcl-2 family includes anti-apoptotic (e.g., Bcl-2 and Bcl-extra large) and pro-apoptotic (e.g., Bcl-associated X and Bcl-2 homologous antagonist killer) proteins, which serve a crucial role in mitochondria-driven cell death (14). In addition, previous reports have shown that Bcl-2 can inhibit the apoptosis induced by chemotherapeutic agents (15-17).

Wilms' tumor protein (WT1) was originally identified as a tumor suppressor gene mapping to the chromosome $11 \mathrm{p} 13$ locus (18). The WT1 gene product is a transcription factor with a proline-glutamine rich domain at the $\mathrm{N}$-terminus and a zinc finger domain at the C-terminus. The WT1 gene yields four alternative splice variants: WT1-A [17 amino acids (AA) ${ }^{-/ 3}$ AA lysine-threonine-serine (KTS) ${ }^{-}$; WT1-B [17 AA $^{+} / \mathrm{KTS}^{-}$; WT1-C [17 $\left.\mathrm{AA}^{-} / \mathrm{KTS}^{+}\right]$; and WT1-D [17 $\left.\mathrm{AA}^{+} / \mathrm{KTS}^{+}\right]$(19). Previous studies have indicated that the WT1 protein upregulates or downregulates Bcl-2, depending on the cell-type and/or isoform of WT1 $(20,21)$. The WT1 gene was also overexpressed in multiple types of solid tumor and primary human leukemia (12,22-26), and high expression levels of WT1 mRNA were associated with poor prognosis in leukemia and breast cancer $(22,27)$.

Mayo et al (21) revealed that the stable expression of the WT1-B isoform resulted in elevated endogenous Bcl-2 protein in rhabdoid cells. However, roles for WT1 and Bcl-2 in the DAC-mediated potentiation of CPT-11/SN-38 antitumor activity have not been elucidated in human CRC cells.

The present study aimed to clarify the association between this potentiation of antitumor activity and the WT1-Bcl-2 pathway by RNA interference-mediated knockdown of WT1 using the human CRC cell lines, HCT116 and HT29.

\section{Materials and methods}

Cell lines and culture conditions. Human colon carcinoma HCT116 (No. CCL-247) and human colon adenocarcinoma HT29 (No. HTB-38) cell lines were obtained from DS Pharma Biomedical Co., Ltd. (Osaka, Japan). These cell lines were cultured in Dulbecco's modified Eagle's medium (DMEM; Gibco; Thermo Fisher Scientific, Inc., Waltham, MA, USA) supplemented with $10 \%$ fetal bovine serum (FBS; Hyclone; GE Healthcare Life Sciences, Logan, UT, USA) and 1\% antibiotic-antimycotic (Gibco; Thermo Fisher Scientific, Inc.) at $37^{\circ} \mathrm{C}$ in a $5 \% \mathrm{CO}_{2}$ incubator.

Regents. CPT-11 was purchased from Toronto Research Chemicals, Inc. (Toronto, ON, Canada) and SN-38 was purchased from Tocris Bioscience (Bristol, UK). CPT-11 and SN-38 were dissolved in dimethyl sulfoxide and stored at $-30^{\circ} \mathrm{C}$. DAC was obtained from Sigma-Aldrich; Merck KGaA (Darmstadt, Germany), dissolved in Milli-Q water (Direct-Q $\mathrm{UV}$; Merck $\mathrm{KGaA}$ ), and stored at $-30^{\circ} \mathrm{C}$.

Drug exposure. For each experiment, HCT116 and HT29 cells were exposed for 10 days to either vehicle alone (control), CPT-11 alone, SN-38 alone, DAC alone, CPT-11 plus DAC, or SN-38 plus DAC. The drug concentrations used for the colony-forming assay were $62.5,125,250$ or $500 \mathrm{nM}$ CPT-11; $0.35,0.5,0.7$ or $1.0 \mathrm{nM} \mathrm{SN}-38$; and $31.25 \mathrm{nM}$ DAC in HCT116 cells. For HT29 cells, the drug concentrations were 0.5 or
$1.0 \mu \mathrm{M}$ CPT-11; 1.0 or $2.5 \mathrm{nM} \mathrm{SN}-38$; and 75 or $100 \mathrm{nM}$ DAC. In western blot analysis and RNA interference assays utilizing HCT116 cells, the concentrations used were 500 nM CPT-11, $1.0 \mathrm{nM}$ SN-38, and $31.25 \mathrm{nM}$ DAC; the concentrations used for HT29 cells were $500 \mathrm{nM}$ CPT-11, $1.0 \mathrm{nM}$ SN-38, and $75 \mathrm{nM}$ DAC.

Colony-forming assay. HCT116 and HT29 cells were plated at a density of 20,000 and 5,000 cells per $60-\mathrm{mm}$ dish, respectively. Following incubation with each drug for 10 days, the colonies were stained with $0.04 \%$ crystal violet overnight at room temperature and scored. The scored colonies contained more than 50 cells for HCT116 and 30 cells for HT29.

Analysis of drug combination effects. Isobologram analysis was performed using CompuSyn software version 1.0 (ComboSyn, Inc., Paramus, NJ, USA), which enabled the calculation of a combination index (CI) according to the Chou-Talalay CI-Isoblogram theory (28). To assess the combination effects of CPT-11 or SN-38 with DAC, colony-forming assay data were converted to a fraction of growth inhibition by each drug alone or by the drug combinations as compared with control cells. There are two methods of CompuSyn software analyses: constant ratio and non-constant ratio analyses. A constant ratio requires the ratio of $\mathrm{CPT}-11$ and $\mathrm{DAC}$ concentrations in combination experiments to be constant e.g., $500 \mathrm{nM} \mathrm{CPT-11}$ and $31.25 \mathrm{nM}$ DAC or $250 \mathrm{nM}$ CPT-11 and $15.625 \mathrm{nM}$ DAC etc., where CPT-11 concentration is consistently 16 -fold higher than that of DAC, and constant throughout a series of combination experiments. However, in the experimental conditions of the present study, drug concentrations were either 125, 250, or $500 \mathrm{nM}$ CPT-11, with $3.9 \mathrm{nM}$ DAC; 125, 250, or $500 \mathrm{nM}$ CPT-11, with $7.8 \mathrm{nM}$ DAC; 125, 250, or $500 \mathrm{nM}$ CPT-11, with $15.625 \mathrm{nM}$ DAC; 125,250 , or $500 \mathrm{nM}$ CPT-11, with $31.25 \mathrm{nM}$ DAC. Furthermore, for SN-38 and DAC in the present study, the drug concentrations were as follows: Drug concentrations were either $0.35,0.5,0.7$ or $1.0 \mathrm{nM} \mathrm{SN}-38$, plus $3.9 \mathrm{nM}$ DAC; $0.35,0.5,0.7$ or $1.0 \mathrm{nM}$ SN-38, plus $7.8 \mathrm{nM}$ DAC; $0.35,0.5,0.7$ or $1.0 \mathrm{nM} \mathrm{SN-38}$, plus $15.625 \mathrm{nM}$ DAC; $0.35,0.5,0.7$ or $1.0 \mathrm{nM}$ SN-38, plus $31.25 \mathrm{nM}$ DAC. Therefore, drug concentration ratios for the present study were non-constant. CompuSyn automatically created a normalized isobologram by a non-constant ratio analysis (29). The combination index, CI, is theoretically calculated by CompuSyn software according to Equation 1.

$$
\mathrm{CI}=\frac{(D)_{1}}{(D x)_{1}}+\frac{(D)_{2}}{(D x)_{2}}=\frac{(D)_{1}}{\left(D_{m}\right)_{1}\left[f_{a} /\left(1-f_{a}\right]^{1 / m 1}\right.}+\frac{(D)_{2}}{\left(D_{m}\right)_{2}\left[f_{a} /\left(1-f_{a}\right)\right]^{1 / m 2}}
$$

(Equation 1), where (Dx) $)_{1}$, and (Dx) $)_{2}$ are characteristic parameters for either CPT-11 or SN-38, and DAC, respectively, and fa, a fraction of growth inhibition (i.e., 1-colony formation rate). By the median-effect plot $(28,29), \log (\mathrm{Dm})_{1}$, and $1 / \mathrm{m}_{1}$ were computationally calculated using various concentrations [i.e., (D) ] of DAC in single drug treatments. Similarly, $\log (\mathrm{Dm})_{2}$, and $1 / \mathrm{m}_{2}$ were computationally calculated using various concentrations [i.e., (D) $)_{2}$ of CPT-11 or SN-38. Furthermore, in combination experiments, CI values were computationally calculated using drug concentrations that were used for combination experiments i.e., concentration of DAC, (D) $)_{1}$, and concentration of CPT-11 or SN-38 (D) $)_{2}$, and experimentally observed fa. $(\mathrm{Dm})_{1}, \mathrm{~m}_{1},(\mathrm{Dm})_{2}$, and $\mathrm{m}_{2}$, are 
constants obtained from single drug treatment experiments. Normalized isobolograms, whose $\mathrm{X}$-axis was $(\mathrm{D})_{1} /(\mathrm{Dx})_{1}$, and Y-axis was $(D)_{2} /(D x)_{2}$ were created.

Western blotting. HCT116 and HT29 cells were cultured for 6 days following initiation of the drug treatment and solubilized in radioimmunoprecipitation assay buffer $(50 \mathrm{mM}$ Tris- $\mathrm{HCl}$, $150 \mathrm{mM} \mathrm{NaCl}, 0.5 \%$ deoxycholate, $1 \% \mathrm{NP}-40$ and $0.1 \%$ SDS). The protein samples were separated by $10 \%$ SDS-PAGE (equal amounts of total protein, $20 \mu \mathrm{g}$ per lane) and transferred onto PVDF membranes. Protein concentrations of the samples were quantified by Bradford assay using Bio-Rad Protein Assay Dye Reagent Concentrate (catalog no. \#5000006, Bio-Rad Laboratories, Inc., Hercules, CA, USA). The membranes were blocked with Blocking One (Nacalai, Kyoto, Japan) at room temperature for $90 \mathrm{~min}$ and rinsed with TBS-T (Tris-buffered saline with $0.1 \%$ Tween-20). The membranes were then incubated overnight at $4^{\circ} \mathrm{C}$ with primary antibodies for Bcl-2 (1:500 dilution, kindly provided by Professor Chihaya Maesawa of Iwate Medical University, Morioka, Japan), WT1 (1:200 dilution; cat. no. M3561, Clone 6F-H2; Dako; Agilent Technologies, Inc., Santa Clara, CA, USA), or $\beta$-actin (1:1,000 dilution; cat. no. A1978, Sigma-Aldrich; Merck KGaA) in Can Get Signal Solution 1 (Toyobo Life Science, Osaka, Japan). The blots were incubated for $90 \mathrm{~min}$ with horseradish peroxidase-conjugated mouse-IgG secondary antibody (1:1,000 dilution; cat. no. 616529; Invitrogen; Thermo Fisher Scientific, Inc.) in Can Get Signal Solution 2 (Toyobo Life Science) at room temperature for $2 \mathrm{~h}$. The blots were then washed with TBS-T and visualized with a ChemiDox ${ }^{\mathrm{TM}}$ XRS+ with Image Lab ${ }^{\mathrm{TM}}$ software version 4.0 (Bio-Rad Laboratories, Inc.) following incubation with a chemiluminescent reaction using Clarify ${ }^{\mathrm{TM}}$ Western ECL substrate (Bio-Rad Laboratories, Inc.). Following detection, the protein band intensity was quantified using ImageJ software version 1.48 (National Institutes of Health, Bethesda, MD, USA).

RNA interference. Small interfering RNA (siRNA) was used to downregulate WT1 gene expression in HCT116 cells by transfection of RNA oligonucleotides with Lipofectamine ${ }^{\mathrm{TM}}$ RNAiMAX (Invitrogen; Thermo Fisher Scientific, Inc.). siRNA sequences were constructed to target human WT1 mRNA (Sequences 5'-3', forward: CCAAAGGAGACAUAC AGGUGUGAAA; and reverse: UUUCACACCUGUAUG UCUCCUUUGG: catalog no. HSS111390; Invitrogen; Thermo Fisher Scientific, Inc.), and control siRNAs were designed by scrambling those nucleotide sequences. Control siRNAs were not homologous to any other gene (MISSION ${ }^{\circledR}$ siRNA Universal Negative Control \#1, SIC001-10; Sigma-Aldrich; Merck KGaA). The cells were plated in $3 \mathrm{ml}$ of DMEM $(100,000$ cells per $\mathrm{ml})$ on a $60-\mathrm{mm}$ dish with or without a $100 \mathrm{nM}$ (final concentration) siRNA mixture in the presence of $10 \mu \mathrm{l}$ Lipofectamine. At 12 and $24 \mathrm{~h}$ following the addition of WT1-targetting siRNA to the cells, the WT1 and Bcl-2 protein expression levels were analyzed by western blotting. Following detection, the protein band intensity was quantified using ImageJ software version 1.48.

Statistical analysis. Data on each colony formation rate of drug-treated HCT116 cells were expressed as the mean \pm standard deviation. Data were compared between
CPT-11 or SN-38 alone and in combination with DAC using Student's t-test. In the same way, data on each colony formation rate of drug-treated HT29 cells were expressed as the mean and SD, and compared between each anticancer drug alone and combination with DAC using one-way analysis of variance (ANOVA) followed by Tukey's test.

Data on the protein expression level of Bcl-2 and WT1 in the various drug-treated cells were compared between control, CPT-11 or SN-38 alone, and combination with DAC treatments by one-way ANOVA followed by Dunnett's test. $\mathrm{P}<0.05$ was considered to indicate a statistically significant difference.

\section{Results}

Enhancement of antitumor activity of CPT-11 and SN-38 by DAC in HCT116 cells. The antitumor effects of CPT-11 and its active metabolite SN-38 were investigated with the potential enhancer DAC in the HCT116 and HT29 human CRC cell lines by assessing colony formation. As depicted in Fig. 1A and $\mathrm{B}$, concentration-dependent antitumor activity of CPT-11 (62.5-500 nM) and SN-38 (0.35-1.0 nM) was observed. DAC $(31.25 \mathrm{nM})$ exhibited a tendency to potentiate the antitumor activity of CPT-11 (not statistically significant; Fig. 1A) and SN-38 (with statistical significance $(\mathrm{P}<0.05)$ at $1.0 \mathrm{nM}$, Fig. 1B) in HCT116 cells. CPT-11 suppressed colony formation to $91.6 \%$ at $62.5 \mathrm{nM}$, to $81.6 \%$ at $125 \mathrm{nM}$, to $56.7 \%$ at $250 \mathrm{nM}$, and to $28.7 \%$ at $500 \mathrm{nM}$ in the absence of CPT-11. On the other hand, the presence of DAC and CPT-11 suppressed colony formation to $75.5 \%$ at $62.5 \mathrm{nM}$, to $63.7 \% 125 \mathrm{nM}$, to $40.8 \% 250 \mathrm{nM}$ and to $14.1 \%$ at $500 \mathrm{nM}$. SN-38 suppressed colony formation to $84.8 \%$ at $0.35 \mathrm{nM}$, to $76.6 \%$ at $0.5 \mathrm{nM}$, to $56.0 \%$ at $0.7 \mathrm{nM}$, and to $33.1 \%$ and $1.0 \mathrm{nM}$ without DAC. The presence of DAC plus SN-38 suppressed colony formation to $60.9 \%$ at $0.35 \mathrm{nM}$, to $53.7 \%$ at $0.5 \mathrm{nM}$, to $36.4 \%$ at $0.7 \mathrm{nM}$, and to $15.6 \%$ at $1.0 \mathrm{nM}$. The antitumor effect elicited by the combination of $1.0 \mathrm{nM} \mathrm{SN}-38$ and $31.25 \mathrm{nM}$ DAC was stronger than that at $1.0 \mathrm{nM} \mathrm{SN-38}$ alone with statistical significance $(\mathrm{P}<0.05)$. Treatment with DAC alone only slightly inhibited colony formation in HCT116 cells, with no statistical significance observed (Fig. 1A and B). By contrast, HT29 cells were 2-fold less sensitive to CPT-11 (0.5-1.0 $\mu \mathrm{M})$ and 2.5-fold less sensitive to $\mathrm{SN}-38(1.0-2.5 \mathrm{nM})$ than HCT116 cells (Fig. 1C and D). In the absence of DAC, CPT-11 suppressed colony formation to $78.0 \%$ at $0.5 \mu \mathrm{M}$ and to $24.6 \%$ at $1 \mathrm{mM}$, whereas SN-38 suppressed colony formation to $85.0 \%$ at $1.0 \mathrm{nM}$ and to $33.1 \%$ at $2.5 \mathrm{nM}$. In combination with DAC, no enhancement of antitumor activity was observed for either CPT-11 or SN-38 (Fig. 1C and D).

Synergistic antitumor activity induced by $S N-38$ and DAC in HCT116 cells. Fig. 1 demonstrates that the antitumor activity of CPT-11 and SN-38 was enhanced by DAC in HCT116 cells. These data indicate that CPT-11 or SN-38 combined with DAC might synergize to inhibit cell survival. To examine synergism, the enhancement of CPT-11- and SN-38-mediated antitumor activity was analyzed in the presence of various concentrations of DAC by creating isobolograms with CompuSyn software. Using this isobologram type, the combined effects of the two drugs were summarized as follows: CI values $<1.0$ (points in the lower left),$=1.0$ (points on the hypotenuse) and $>1.0$ (points in 

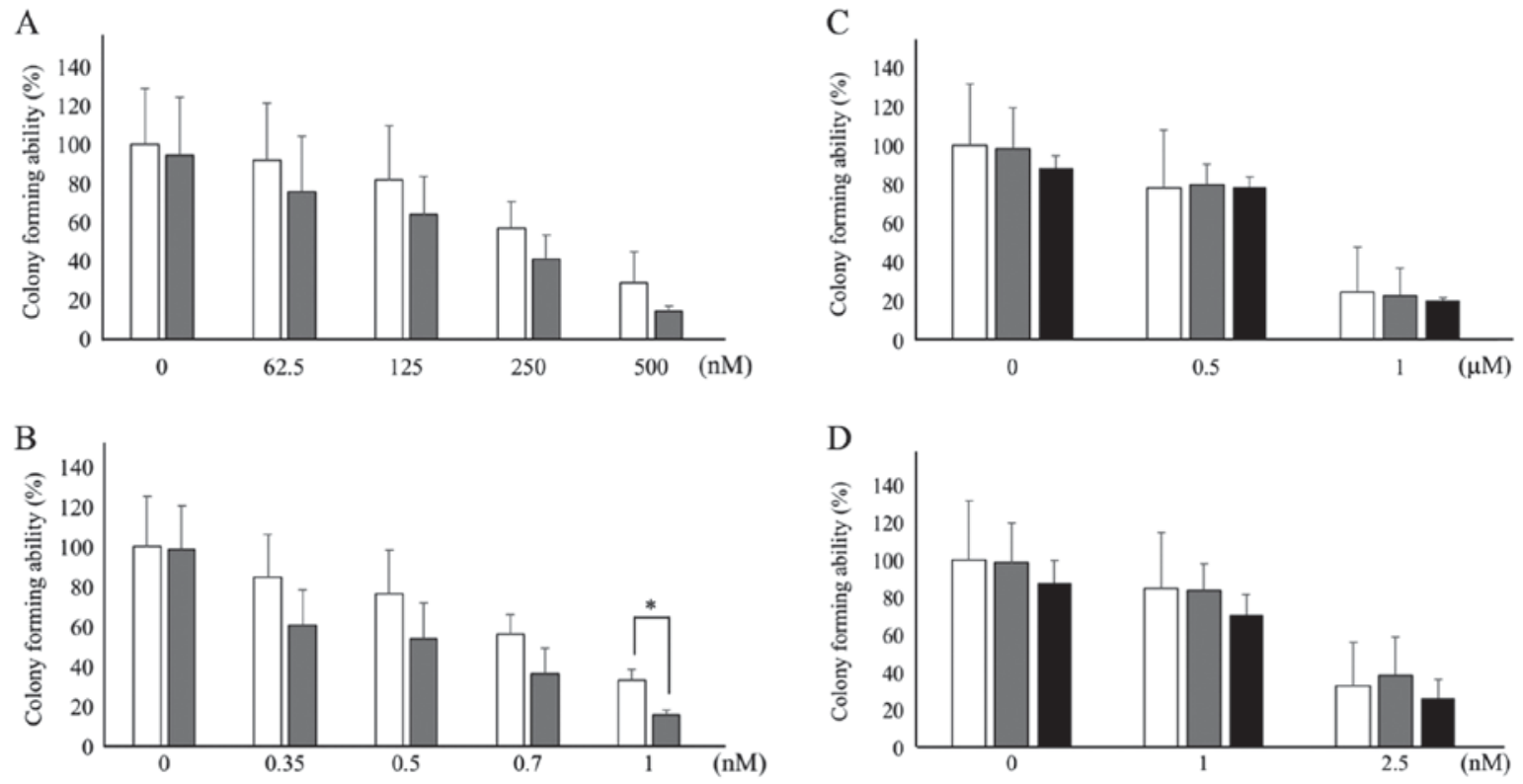

Figure 1. Effect of DAC on the colony formation rate of CPT-11 (A) or SN-38 (B) in human colon cancer HCT116 cell line. Each white bar represents antitumor agent alone at each indicated concentration, and each gray bar represents a combination with DAC (31.25 nM) with each indicated antitumor agent. Effect of DAC on the colony formation rate of CPT-11 (C) or SN-38 (D) in human colon cancer HT29 cell line. White bar, antitumor agent alone at each indicated concentration; gray or black bars represent combination with 75 (gray) or $100 \mathrm{nM}$ (black) DAC with each indicated antitumor agent. X-axis represents drug concentrations [i.e., (A) and (C), CPT-11; and (B) and (D), SN-38]. Data are expressed as mean \pm standard deviation. ${ }^{*} \mathrm{P}<0.05$ (Student's t-test in HCT116 cells). DAC, 5-aza-2'-deoxycytidine; CPT-11, irinotecan; SN-38, 7-ethyl-10-hydroxycamptothecin.

the upper right) respectively indicated synergistic, additive and antagonistic effects $(28,29)$. The combination of CPT-11 and DAC was mostly additive when evaluated using isobolograms (Fig. 2A). The normalized isobologram for the combination of SN-38 and DAC demonstrates synergism of the antitumor activity (Fig. 2B). The ranges of concentrations exhibiting synergism were $0.35-1.0 \mathrm{nM}$ for $\mathrm{SN}-38$ and 3.9-7.8 $\mathrm{nM}$ for DAC.

Protein expression levels of Bcl-2 in HCT116 cells and HT29 cells treated with CPT-11, SN-38, and DAC, alone and in combination. Several lines of evidence have indicated that intracellular Bcl-2 protein levels are associated with the resistance of cancer cells to CPT-11 and SN-38 (30,31). These previous studies indicated that Bcl-2 expression is associated with cancer cell sensitivities to anticancer drugs. Therefore, the expression of Bcl-2 protein in HCT116 and HT29 cells was examined. Fig. 3A and B depict Bcl-2 protein expression in HCT116 cells. Bcl-2 protein levels were marginally downregulated in cells exposed to $0.5 \mu \mathrm{M}$ CPT-11, $1.0 \mathrm{nM} \mathrm{SN-38}$ and $31.25 \mathrm{nM}$ DAC. Combination treatment of $31.25 \mathrm{nM}$ DAC with either $0.5 \mu \mathrm{M}$ CPT-11 or $1.0 \mathrm{nM} \mathrm{SN-38}$ resulted in Bcl-2 protein levels that were almost under the limit of detection. Protein band intensity was determined using by ImageJ software following normalization to $\beta$-actin. $\mathrm{Bcl}-2$ protein expression levels were suppressed to $62.7 \%$ with CPT-11 alone, $66.7 \%$ with SN-38 alone, $50.0 \%$ with DAC alone, $7.8 \%$ with CPT-11 plus DAC, and 6.9\% with $\mathrm{SN}-38$ plus DAC, when compared with control samples (Fig. 3B). The combination of DAC and either CPT-11 or SN-38 most strongly inhibited colony formation by HCT116 cells, an observation consistent with previous work demonstrating that cancer cell resistance to CPT-11 was associated with $\mathrm{Bcl}-2$ overexpression in the human lung cancer cell SBC-3/Bcl-2 subline and the human leukemia cell multidrug resistant HL-60-Vinc subline $(30,31)$. Changes in Bcl-2 protein expression in HT29 cells were also examined following exposure to the drugs, where no DAC-mediated potentiation of CPT-11/SN-38 antitumor activity was observed. Bcl-2 protein levels in the HT29 cells were under the limit of detection, at least 10 times lower than those in the HCT116 cells (Fig. 3C). Under these conditions, possible changes in Bcl-2 protein expression for cells treated with CPT-11, SN-38, DAC, CPT-11 with DAC, and SN-38 with DAC were not detectable.

WT1 protein expression levels in two CRC cell lines treated with CPT-11, SN-38 and DAC, alone and in combination. WT1 was reported to reverse antitumor drug-induced apoptosis by transcriptionally upregulating Bcl-2 (21). The expression of the WT1 protein was examined in HCT116 and HT29 cells. Fig. 4A indicates that the WT1 protein was marginally downregulated in the HCT116 cells exposed to $0.5 \mu \mathrm{M}$ CPT-11, $1.0 \mathrm{nM} \mathrm{SN-38}$, and $31.25 \mathrm{nM}$ DAC. Most evidently, the combination of $31.25 \mathrm{nM}$ DAC and either $0.5 \mu \mathrm{M}$ CPT-11 or $1.0 \mathrm{nM} \mathrm{SN-38}$ resulted in WT1 protein levels that were as low as the limit of detection. The WT1 protein levels were decreased, as estimated by ImageJ software following normalization to $\beta$-actin. WT1 expression was suppressed to $79.2 \%$ at $0.5 \mu \mathrm{M}$ CPT-11, $71.1 \%$ at $1.0 \mathrm{nM}$ $\mathrm{SN}-38,62.9 \%$ at $31.25 \mathrm{nM}$ DAC, $14.0 \%$ with CPT-11 plus DAC, and $8.0 \%$ with SN-38 plus DAC (Fig. 4A and B).

These downregulation profiles of WT1 expression were quite similar to those of the Bcl-2 protein (Fig. 3A and B). Low-level expression of Bcl-2 in HT29 cells led us to examine whether expression of WT1, a Bcl-2 regulator, was similarly low in HT29 cells. Notably, WT1 protein expression was observed at a level close to that observed in HCT116 cells. The expression level of WT1 decreased to $81.4 \%$ upon treatment with $0.5 \mu \mathrm{M}$ 
A

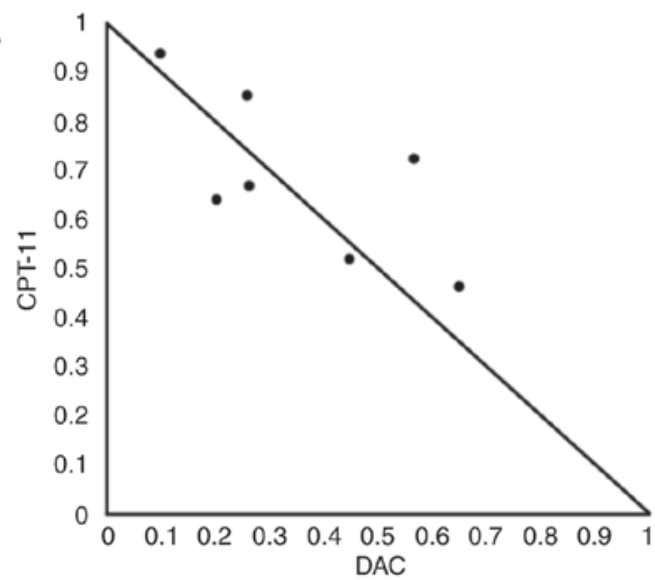

B

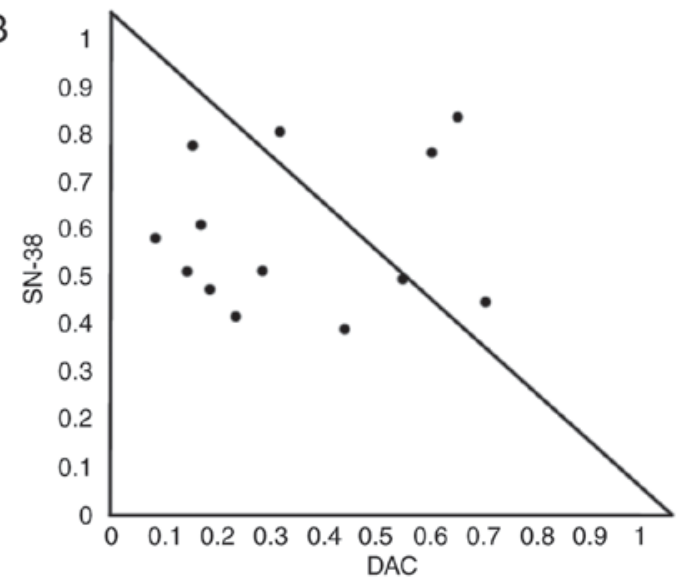

Figure 2. Normalized isobologram for CPT-11/SN-38 and DAC in HCT116 cells. CI for various combinations of DAC (3.9-31.25 nM) and either CPT-11 (125, 250 and $500 \mathrm{nM})$ or SN-38 $(0.35,0.5,0.7$ and $1.0 \mathrm{nM})$. Cells were treated with various concentrations of (A) CPT-11 and DAC, or (B) SN-38 and DAC. The combination effects can be summarized as follows: $\mathrm{CI}<1$, dots located lower left; $\mathrm{CI}=1$, dots on the hypotenuse; and $\mathrm{CI}>1$, dots located upper right; these results indicate synergistic, additive, and antagonistic effects, respectively. DAC, 5-aza-2'-deoxycytidine; CPT-11, irinotecan; SN-38, 7-ethyl-10-hydroxycamptothecin; CI, combination index.

CPT-11, to $67.2 \%$ upon treatment with $1.0 \mathrm{nM} \mathrm{SN-38,53.2 \%}$ upon treatment with $75 \mathrm{nM}$ DAC, $21.4 \%$ upon treatment with $0.5 \mu \mathrm{M}$ CPT-11 and $75 \mathrm{nM}$ DAC, and $13.1 \%$ upon treatment with $1.0 \mathrm{nM} \mathrm{SN}-38$ and $75 \mathrm{nM}$ DAC (Fig. 4C and D).

Knockdown of WT1 suppressed Bcl-2 protein expression in HCT116 cells. Since the association between WT1 and Bcl-2 in CRC cells remains unclear, a WT1-targeted siRNA was utilized to assess WT1 function in HCT116 cells. Knockdown of WT1 was confirmed at the protein level from 12 and $24 \mathrm{~h}$ following treatment with $100 \mathrm{nM}$ siRNA, with $88.2 \%$ suppression of WT1 at $12 \mathrm{~h}$ as compared with non-transfected control and $88.8 \%$ suppression as compared with control (scrambled) siRNA-transfected cells. At $24 \mathrm{~h}$, the extent of WT1 suppression was as low as $66.1 \%$ as compared to the non-transfected control, and as low as $71.2 \%$ as compared with the control siRNA-transfected cells (Fig. 5). WT1 expression was markedly reduced within $12 \mathrm{~h}$ of the application of the WT1 siRNA and was rapidly restored by $24 \mathrm{~h}$. Anti-apoptotic Bcl-2 protein levels at 12 and $24 \mathrm{~h}$ were also suppressed following the application of WT1 siRNA. Bcl-2 proteins were suppressed to $44.6 \%$ when compared with the non-transfected control and $55.8 \%$ when compared with the control siRNA-transfected cells at $12 \mathrm{~h}$. At $24 \mathrm{~h}$, the extent of Bcl-2 suppression was $62.3 \%$ when compared with the non-transfected control and $66.9 \%$ compared with the control siRNA-transfected group (Fig. 5). These results clearly indicated that WT1 functions as a positive regulator of Bcl-2 in human CRC HCT116 cells.

\section{Discussion}

The present study revealed that two different human colon cancer cell lines, HCT116 and HT29, exhibited different profiles for the DAC-mediated potentiation of CPT-11/SN-38 antitumor activity, as measured by colony-formation assays. A statistically significant antitumor potentiation of CPT-11/SN-38 by DAC was demonstrated in HCT116 cells (Fig. 1A and B); however, no appreciable effect was observed by the same combination in HT29 cells (Fig. 1C and D). HCT116 cells continuously exposed to various
A

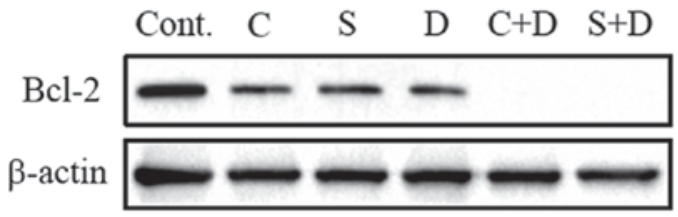

B

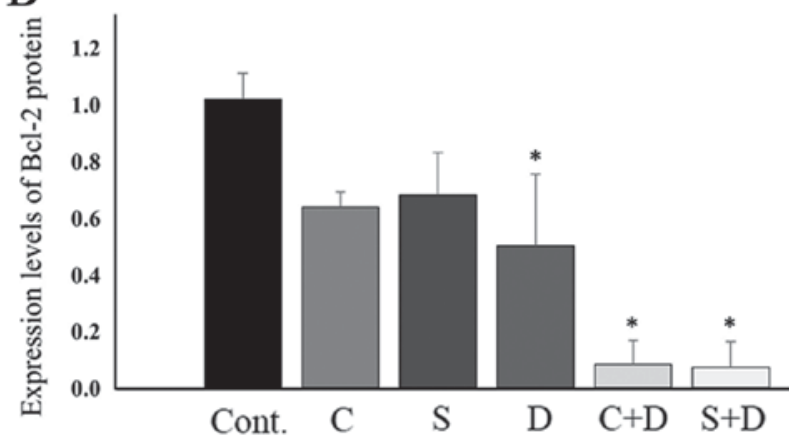

C

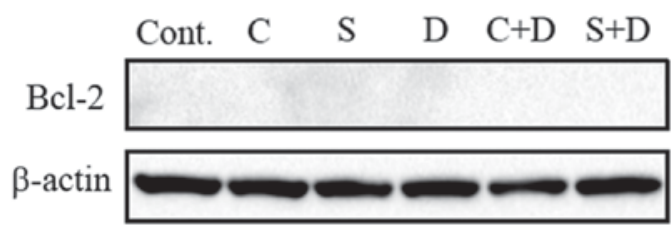

Figure 3. Protein expression levels of Bcl-2. (A) The apoptosis-associated protein Bcl-2 expression levels in HCT116 cells. Cells were treated with $31.25 \mathrm{nM}$ DAC and either CPT-11 or SN-38. $\beta$-actin was used as a control. (B) Bcl-2 protein expression levels following normalization to $\beta$-actin. (C) Bcl-2 protein expression levels in HT29 cells treated with $75 \mathrm{nM}$ DAC and either CPT-11 or SN-38. Cellular proteins were extracted 6 days after the start of culture. Data are expressed as mean \pm standard deviation. ${ }^{*} \mathrm{P}<0.05$ (one-way analysis of variance followed by Dunnett's test). Bcl-2, B-cell lymphoma-2; DAC, 5-aza-2'-deoxycytidine; CPT-11, irinotecan; SN-38, 7-ethyl-10-hydroxycamptothecin; Cont., vehicle control; C, $0.5 \mu \mathrm{M} \mathrm{CPT-11;}$ S, $1.0 \mathrm{nM} \mathrm{SN}-38$; D, 31.25 (for HCT116 cells) or $75 \mathrm{nM}$ (for HT29 cells) DAC.

concentrations of CPT-11/SN-38 and $31.25 \mathrm{nM}$ DAC for 10 days had a plating efficiency lower than that of the respective control cells, which were treated with CPT-11/SN-38 alone (Fig. 1A and 
A

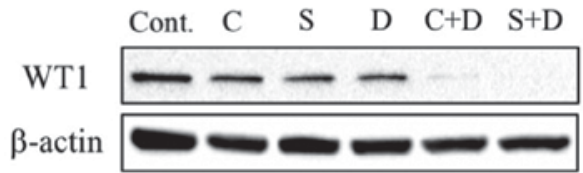

B

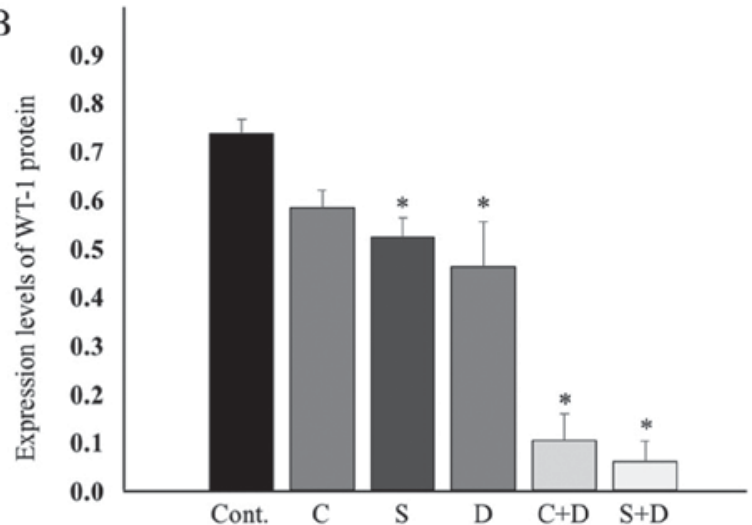

C

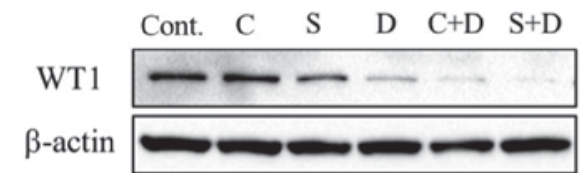

$\mathrm{D}$

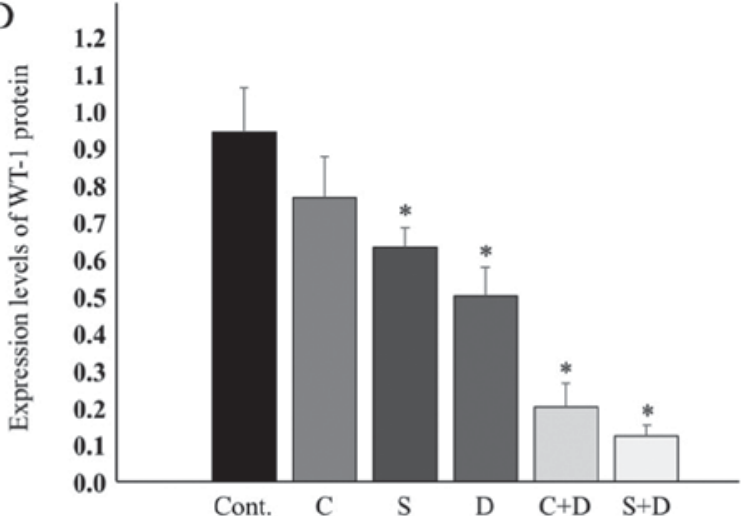

Figure 4. WT1 protein expression and quantification in (A and B) HCT116 cells and (C and D) HT29 cells. (B) and (D) Quantification was performed by normalization to $\beta$-actin. The DAC concentration used was $31.25 \mathrm{nM}$ for HCT116 and $75 \mathrm{nM}$ for HT29. Data are expressed as mean \pm standard deviation. * $\mathrm{P}<0.05$ (one-way analysis of variance followed by Dunnett's test). WT1, Wilms' tumor protein; DAC, 5-aza-2'-deoxycytidine; CPT-11, irinotecan; SN-38, 7-ethyl-10-hydroxycamptothecin; Cont., vehicle control; C, $0.5 \mu \mathrm{M}$ CPT-11; S, 1.0 nM SN-38; D, 31.25 for HCT116 cells; Fig. 4B. or 75 nM for HT29 cells; Fig. 4D. DAC.

B). In these experiments, it is noteworthy that $31.25 \mathrm{nM}$ DAC exhibited essentially no cytotoxicity in HCT116 cells. This DAC concentration was at least one order of magnitude lower than clinically achieved plasma concentrations $(\sim 360-660 \mathrm{nM})$ in a phase I clinical trial study ( $1 \mathrm{~h}$ infusion with a dose of $45 \mathrm{mg} / \mathrm{m}^{2}$ ) when used in combination with carboplatin in solid tumors, performed in the United Kingdom (32) and that achieved in a phase I/II study of DAC ( $1 \mathrm{~h}$ infusion with a dose of $\left.15-20 \mathrm{mg} / \mathrm{m}^{2}\right)$ in patients with myelodysplastic syndrome, performed in Japan (33). The potentiation of CPT-11/SN-38 antitumor activity by DAC was also examined to identify possible synergism, according to the Chou-Talalay method utilizing the CI-Isoblogram theory (28). The results of this analysis indicated that while a combination of CPT-11 and DAC was additive, a combination of SN-38 and DAC yielded synergistic effects in HCT116 cells.

Differences in the expression of proteins with pro-apoptotic or anti-apoptotic functions were examined in HCT116 and HT29 cells. Notably, the level of Bcl-2 protein, an apoptosis-suppressing factor, was markedly different in the two cell lines (Fig. 3A and C). Bcl-2 protein expression was marginally downregulated by $37.3,33.3$, and $50.0 \%$ by the single-drug administrations of CPT-11, SN-38, and DAC, respectively. By contrast, Bcl-2 proteins were heavily downregulated in the drug combination groups with a $92.2 \%$ reduction induced by treatment with CPT-11 and DAC and a $93.1 \%$ reduction by treatment with SN-38 and DAC in HCT116 cells following a 6-day exposure (Fig. 3A). By contrast, Bcl-2 protein levels in HT29 cells were barely detectable (Fig. 3C).

WT1 was reported to function as a Bcl-2 transcriptional regulatory factor $(20,21)$ and is overexpressed in several solid tumors (12,23-26). Preliminary studies reported that WT1 exists in four isoforms, each of which can regulate the $\mathrm{Bcl}-2$ gene in a positive or a negative way, depending on the cancer cell type $(20,21)$. The heterologous expression of WT1 in HeLa cells led to the repression of Bcl-2 promoters, demonstrating negative regulation of Bcl-2 by WT1 in HeLa cells (20).

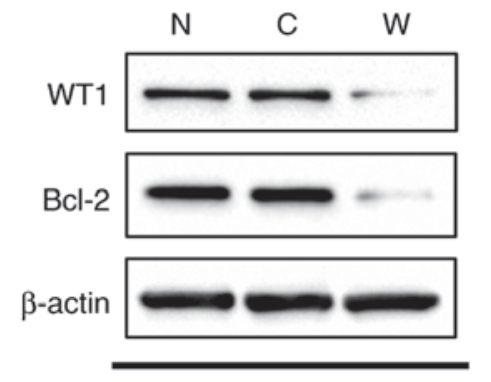

$12 \mathrm{~h}$

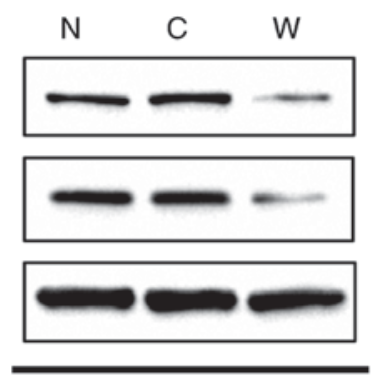

$24 \mathrm{~h}$
Figure 5. WT1 knockdown in HCT116 cells. After 12 or $24 \mathrm{~h}$ of transfection, the WT1 and Bcl-2 protein expressions were analyzed by western blotting. WT1, Wilms' tumor protein; Bcl-2, B-cell lymphoma-2; siRNA, small interfering RNA; N, non-transfected; C, control scrambled siRNA; W, WT1-targetinng siRNA.

Rhabdoid cell lines stably expressing the WT1-B isoform [17 $\left.\mathrm{AA}^{+} / \mathrm{KTS}^{-}\right]$resulted in increased expression of $\mathrm{Bcl}-2$ proteins, indicating positive regulation of $\mathrm{Bcl}-2$ expression by WT1 in a Rhabdoid cell model (21). Tatsumi et al (34), using a WT1-downregulating short hairpin RNA as a potent apoptosis-inducing agent, demonstrated that WT1 isoforms with exon $5\left[17 \mathrm{AA}^{+} / \mathrm{KTS}^{+}\right.$and $\left.17 \mathrm{AA}^{+} / \mathrm{KTS}^{-}\right]$were anti-apoptotic proteins in WT1-expressing cell-lines (including fibrosarcoma HT-1080, lung cancer LU99B, gastric cancer AZ-521, and glioblastoma A172 cells), but not WT1-non-expressing cell lines (including gastric cancer MKN28, cervical cancer HelaAG and lung cancer PC14 cells).

To understand the role of WT1 on Bcl-2 expression in a human CRC cell line, WT1 protein expression levels in HCT116 cells and associated changes in Bcl-2 protein levels were analyzed using a WT1-targeted siRNA. Downregulation of WT1 protein expression was observed at $12 \mathrm{~h}$ after the application of the WT1 siRNA, although protein expression was restored after $24 \mathrm{~h}$. Bcl-2 protein expression was also 
examined at 12 and $24 \mathrm{~h}$. While WT1 protein was forcibly downregulated to $11-12 \%$ by WT1-targeting siRNA at $12 \mathrm{~h}$ after the addition of the WT1 siRNA, Bcl-2 protein expression was downregulated to $45-56 \%$. At $24 \mathrm{~h}$ after the WT1 siRNA addition, expressions of WT1 and Bcl-2 were restored to 66-71 and $62-67 \%$, respectively. These results led to the conclusion that WT1 positively regulated Bcl-2 expression in the HCT116 human CRC cell line.

In experiments using HCT116 cells, an additive antitumor effect was observed when a combination of CPT-11 and DAC was used, whereas synergism was observed when a combination of SN-38 and DAC was used. By contrast, no such potentiation of antitumor activity was observed in the human CRC HT29 cell line. In HCT116 cells, it was demonstrated that $\mathrm{WT} 1$ acts as a positive $\mathrm{Bcl}-2$ regulator. Expression of WT1 and Bcl-2 were markedly downregulated in cells exposed to a combination of CPT-11 or SN-38 with DAC, when compared with those in cells exposed to CPT-11, SN-38 or DAC alone. Given the low level of cytotoxicity observed in HCT116 cells with $31.25 \mathrm{nM}$ DAC alone, it was notable that downregulation of WT1 and Bcl-2 was dependent on the presence of this non-cytotoxic concentration of DAC. Detailed molecular mechanisms for the DAC-mediated potentiation of CPT-11 or SN-38 cytotoxicity and the resultant downregulation of WT1 and Bcl-2 in HCT116 cells have not been elucidated. However, the HT29 cells, in which the expression level of $\mathrm{Bcl}-2$ was much lower than that in HCT116 cells, failed to exhibit potentiation of the antitumor activity. We hypothesize that even though WT1 is expressed in HT29 cells, the low level of Bcl-2 expression might be insufficient for the potentiation of this activity, indicating a requirement for participation of the WT1-Bcl-2 pathway in this process.

In conclusion, the known DNA methyltransferase inhibitor DAC sensitized the human CRC HCT116 cell line to CPT-11 and SN-38, likely through the downregulation of the WT1-Bcl-2 pathway. The extent of the DAC-dependent sensitization may be associated with $\mathrm{Bcl}-2$ expression levels in CRC cells, which is dependent on the characteristics of the individual carcinoma cells.

\section{Acknowledgements}

The authors would like to thank Dr Shinji Yasuhira and Professor Chihaya Maesawa (Department of Tumor Biology, Institute of Biomedical Science, Iwate Medical University, Morioka, Japan) for providing anti-Bcl-2 antibodies for western blot analysis.

\section{Competing interests}

The authors declare that they have no competing interests.

\section{References}

1. Stewart BW and Wild CP(eds); International Agency for Research on Cancer, WHO: World Cancer Report 2014. http://www. thehealthwell.info/node/725845. Accessed January 18, 2018

2. Kawato Y, Aonuma M, Hirota Y, Kuga $\mathrm{H}$ and Sato K: Intracellular roles of $\mathrm{SN}-38$, a metabolite of the camptothecin derivative CPT-11, in the antitumor effect of CPT-11. Cancer Res 51: 4187-4191, 1991.
3. Tanizawa A, Fujimori A, Fujimori Y and Pommier Y: Comparison of topoisomerase I inhibition, DNA damage, and cytotoxicity of camptothecin derivatives presently in clinical trials. J Natl Cancer Inst 11: 836-842, 1994.

4. Hsiang YH, Lihou MG and Liu LF: Arrest of replication forks by drug-stabilized topoisomerase I -DNA cleavable complexes as a mechanism of cell killing by camptotecin. Cancer Res 49: 5077-5082, 1989.

5. te Poele RH and Joel SP: Schedule-dependent cytotoxicity of SN-38 in p53 wild-type and mutant colon adenocarcinoma cell lines. Br J Cancer 81: 1285-1293, 1999.

6. Allen WL and Johnston PG: Role of genomic markers in colorectal cancer treatment. J Int Oncol 20: 4545-4552, 2005.

7. Paz MF, Fraga MF, Avila S, Guo M, Pollan M, Herman JG and Esteller M: A systematic profile of DNA methylation in human cancer cell lines. Cancer Res 63: 1114-1121, 2003.

8. Gnyszka A, Jastrzebski Z and Flis S: DNA methyltransferase inhibitors and their emerging role in epigenetic therapy of cancer. Anticancer Res 33: 2989-2996, 2013

9. Tsai HC, Li H, Van Neste L, Cai Y, Robert C, Rassool FV, Shin JJ, Harbom KM, Beaty R, Pappou E, et al: Transient low doses of DNA-demethylating agents exert durable antitumor effects on hematological and epithelial tumor cells. Cancer Cell 21: 430-436, 2012.

10. Ishiguro M, Iida S, Uetake H, Morita S, Makino H, Kato K, Takagi Y, Enomoto $M$ and Sugihara K: Effect of combined therapy with low-dose 5-aza-2'-deoxycytidine and irinotecan on colon cancer cell line HCT-15. Ann Surg Oncol 14: 1752-1762, 2006.

11. Ikehata M, Ogawa M, Yamada Y, Tanaka S, Ueda K and Iwakawa S: Different effects of epigenetic modifiers on the cytotoxicity induced by 5 -fluorouracil, irinotecan or oxaliplatin in colon cancer cells. Biol Pharm Bull 37: 67-73, 2014.

12. Oji Y, Inohara H, Nakazawa M, Nakano Y, Akahani S, Nakatsuka S, Koga S, Ikeba A, Abeno S, Honjo Y, et al: Overexpression of the Wilms' tumor gene WT1 in head and neck squamous cell carcinoma. Cancer Sci 94: 523-529, 2003.

13. Okada K, Hakata S, Terashima J, Gamou T, Habano W and Ozawa S: Combination of the histone deacetylase inhibitor depsipeptide and 5-fluorouracil upregulates major histocompatibility complex class II and p21 genes and activates caspase-3/7 in human colon cancer HCT-116 cells. Oncol Rep 36: 1875-1885, 2016.

14. Tsujimoto Y: Role of Bcl-2 family proteins in apoptosis: Apoptosomes or mitochondria? Genes Cells 3: 697-707, 1998.

15. Kamesaki S, Kamesaki H, Jorgensen TJ, Tanizawa A, Pommier Y and Cossman J: Bcl-2 protein inhibits etoposide-induced apoptosis through its effects on events subsequent to topoisomerase II-induced DNA strand breaks and their repair. Cancer Res 18: 4251-4256, 1993

16. Dole M, Nuñez G, Merchant AK, Maybaum J, Rode CK, Bloch CA and Castle VP: Bcl-2 inhibits chemotherapy-induced apoptosis in neuroblastoma. Cancer Res 12: 3253-3259, 1994.

17. Lou YF, Zou ZZ, Chen PJ, Huang GB, Li B, Zheng DQ, Yu XR and Luo XY: Combination of Gefitinib and DNA methylation inhibitor decitabine exerts synergistic anti-cancer activity in colon cancer cells. PLoS One 9: e97719, 2014.

18. Call KM, Glaser T, Ito CY, Buckler AJ, Pelletier J, Haber DA, Rose EA, Kral A, Yeger H, Lewis WH, et al: Isolation and characterization of a zinc finger polypeptide gene at the human chromosome 11 Wilms' tumor locus. Cell 60: 509-520, 1990.

19. Haber DA, Sohn RL, Buckler AJ, Pelletier J, Call KM and Housman DE: Alternative splicing and genomic structure of the Wilms tumor gene WT1. Proc Natl Acad Sci USA 88: 9618-9622, 1991.

20. Hewitt SM, Hamada S, McDonnell TJ, Rauscher FJ III and Saunders GF: Regulation of the proto-oncogenes bcl-2 and c-myc by the Wilms' tumor suppressor gene WT1. Cancer Res 55: 5386-5389, 1995.

21. Mayo MW, Wang CY, Drouin SS, Madrid LV, Marshall AF, Reed JC, Weissman BE and Baldwin AS: WT1 modulates apoptosis by transcriptionally upregulating the bcl-2 proto-oncogene. EMBO J 18: 3990-4003, 1999.

22. Inoue K, Ogawa H, Sonoda Y, Kimura T, Sakabe H, Oka Y, Miyake S, Tamaki H, Oji Y, Yamagami T, et al: Aberrant overexpression of the Wilms' tumor gene (WT1) in human leukemia. Blood 89: 1405-1412, 1997.

23. Oji Y, Miyoshi S, Maeda H, Hayashi S, Tamaki H, Nakatsuka S, Yao M, Takahashi E, Nakano Y, Hirabayashi $\mathrm{H}$, et al: Overexpression of the Wilms' tumor gene WT1 in de novo lung cancers. Int J Cancer 100: 297-303, 2002. 
24. Oji Y, Yamamoto H, Nomura M, Nakano Y, Ikeba A Nakatsuka S, Abeno S, Kiyotoh E, Jomgeow T, Sekimoto M, et al: Overexpression of the Wilms' tumor gene WT1 in colorectal adenocarcinoma. Cancer Sci 94: 712-717, 2003.

25. Loeb DM, Evron E, Patel CB, Sharma PM, Niranjan B, Buluwela L, Weitzman SA, Korz D and Sukumar S: Wilms tumor suppressor gene (WT1) is expressed in primary breast tumors despite tumor-specific promoter methylation. Cancer Res 61: 921-925, 2001.

26. Oji Y, Nakamori S, Fujikawa M, Nakatsuka S, Yokota A, Tatsumi N, Abeno S, Ikeba A, Takashima S, Tsujie M, et al: Overexpression of the Wilms' tumor gene WT1 in pancreatic ductal adenocarcinoma. Cancer Sci 95: 583-587, 2004.

27. Miyoshi Y, Ando A, Egawa C, Taguchi T, Tamaki Y, Tamaki H, Sugiyama H and Noguchi S: High expression of Wilms' tumor suppressor gene predicts poor prognosis in breast cancer patients. Clin Cancer Res 8: 1167-1171, 2002.

28. Chou TC: Theoretical basis, experimental design, and computerized simulation of synergism and antagonism in drug combination studies. Pharmacol Rev 58: 621-681, 2006.

29. Chou TC: Drug combination studies and their synergy quantification using Chou-Talalay method. Cancer Res 70: 440-446, 2010.
30. Ohmori T, Podack ER, Nishio K, Takahashi M, Miyahara Y, Takeda Y, Kubota N, Funayama Y, Ogasawara H, Ohira T, et al: Apoptosis of lung cancer cells caused by some anti-cancer agents (MMC, CPT-11, ADM) is inhibited by BCL-2. Biochem Biophys Res Commun 192: 30-36, 1993.

31. Palissot V, Belhoussine R, Carpentier Y, Sebille S, Morjani H, Manfait $M$ and Dufer J: Resistance to apoptosis induced by topoisomerase I inhibitors in multidrug-resistant HL60 leukemic cells. Biochem Biophys Res Commun 245: 918-922, 1998.

32. Appleton K, Mackay HJ, Judson I, Plumb JA, McCormick C, Strathdee G, Lee C, Barrett S, Reade S, Jadayel D, et al: Phase I and pharmacodynamic trial of the DNA methyltransferase inhibitor decitabine and carboplatin in solid tumors. J Clin Oncol 25: 4603-4609, 2007.

33. Oki Y, Kondo Y, Yamamoto K, Ogura M, Kasai M, Kobayashi Y, Watanabe T, Uike N, Ohyashiki K, Okamoto S, et al: Phase I/II study of decitabine in patients with myelodysplastic syndrome: A multi-center study in Japan. Cancer Sci 103: 1839-1847, 2012.

34. Tatsumi N, Oji Y, Tsuji N, Tsuda A, Higashio M, Aoyagi S, Fukuda I, Ito K, Nakamura J, Kitamura Y, et al: Wilms' tumor gene WT1-shRNA as a potent apoptosis-inducing agent for solid tumors. Int J Oncol 32: 701-711, 2008. 